\title{
A study of fracture loads and fracture characteristics of teeth
}

\author{
Chang-Yong Sheen ${ }^{1}$, Jin-Keun Dong², William Arthur Brantley ${ }^{3}$, David Seungho Han ${ }^{3 *}$ \\ ${ }^{1}$ Department of Dental Hygiene, College of Health Sciences, Seongnam Campus, Eulji University, Seongnam, Republic of Korea \\ ${ }^{2}$ Department of Prosthodontics, College of Dentistry, Wonkwang University, Iksan, Republic of Korea \\ ${ }^{3}$ Division of Restorative Science and Prosthodontics, College of Dentistry, The Ohio State University, Columbus, OH, USA
}

\begin{abstract}
PURPOSE. The purpose of this in vitro study was to investigate the fracture loads and modes of failure for the full range of natural teeth under simulated occlusal loading. MATERIALS AND METHODS. One hundred and forty natural teeth were taken from mandibles and maxillas of patients. There were 14 groups of teeth with 10 teeth in each group ( 5 males and 5 females). Each specimen was embedded in resin and mounted on a positioning jig, with the long axis of the tooth at an inclined angle of 30 degrees. A universal testing machine was used to measure the compression load at which fracture of the tooth specimen occurred; loads were applied on the incisal edge and/or functional cusp. RESULTS. The mean fracture load for the mandibular first premolar was the highest $(2002 \mathrm{~N})$ of all the types of teeth, while the mean fracture load for the maxillary first premolar was the lowest $(525 \mathrm{~N})$. Mean fracture loads for the mandibular and maxillary incisors, and the first and second maxillary premolars, had significantly lower values compared to the other types of teeth. The mean fracture load for the teeth from males was significantly greater than that for the teeth from females. There was an inverse relationship between age and mean fracture load, in which older teeth had lower fracture loads compared to younger teeth. CONCLUSION. The mean fracture loads for natural teeth were significantly different, with dependence on tooth position and the sex and age of the individual. [J Adv Prosthodont 2019;11:187-92]
\end{abstract}

KEYWORDS: Fracture loads of teeth; Fracture characteristics of teeth

\section{INTRODUCTION}

Teeth, whose main role is mastication, have specific functions, depending on their position in the jaw and their shape. A tooth is composed of the pulp containing nerves and vessels, the dentin containing tubules that receive nutrients from the pulp, and the enamel which is formed from assemblies of aligned microscopic rods. When an external load is delivered to the tooth, the dentin provides support to the enamel. ${ }^{1,2}$

\footnotetext{
Corresponding author:

David Seungho Han

Division of Restorative Science and Prosthodontics College of Dentistry, The Ohio State University, 305 W 12th Ave, Columbus, OH 43210, USA Fax.+17703932312: e-mail, han.10@osu.edu

Received January 24, 2019 / Last Revision April 30, 2019 / Accepted June 11,2019

(C) 2019 The Korean Academy of Prosthodontics

This is an Open Access article distributed under the terms of the Creative Commons Attribution Non-Commercial License (http://creativecommons. org/licenses/by-nc/4.0) which permits unrestricted non-commercial use, distribution, and reproduction in any medium, provided the original work is properly cited.
}

It is common in dental practice to observe tooth fracture resulting from mastication or trauma from extrinsic factors like occlusal overloading against an implant-supported prosthesis, parafunctional loading such as bruxism, or an accidental impact. Tooth fracture can vary from a fractured area at the cusp to a fracture line extending to the root that may require tooth extraction. The mode of fracture differs according to the position, shape, and structure of each tooth. Past studies of tooth fracture have mainly been performed by using teeth that have undergone endodontic treatment. However, there has been very little research investigating the loads that cause fracture of natural teeth. ${ }^{3}$

Strub and Beschnidt ${ }^{4}$ evaluated the fracture resistance of 5 different all-ceramic crown systems. Simulated chewing with thermocycling decreased the fracture strength significantly for all tested crown systems, while there were no significant differences between all-ceramic crown and metal ceramic crown groups. Potiket et al. ${ }^{5}$ compared the fracture resistance of crowns made from 3 different types of 2 allceramic crown systems. There was no significant difference in the fracture strength of teeth restored with all-ceramic crowns having $0.4-$ and $0.6-\mathrm{mm}$ aluminum oxide copings, 
0.6-mm zirconia copings, and with metal ceramic crowns. Attia and $\operatorname{Kern}^{6}$ investigated the influence of 2 bonding procedures on the fracture resistance of low-fusing ceramic crowns and computer-aided design/computer-aided manufacturing (CAD/CAM) all-ceramic crowns. Fracture loads of natural teeth and the $2 \mathrm{CAD} / \mathrm{CAM}$ crowns were significantly higher than the fracture load of the low-fusing ceramic crowns treated with $\mathrm{HF}$ and silane. Al-Omiri ${ }^{7}$ critically analyzed the factors for fracture resistance of teeth restored with dowel-retained restorations. Fracture resistance was improved when (a) tooth structure loss was limited, (b) a ferrule was obtained, (c) a post with similar physical properties to natural dentin was used, and (d) adhesive techniques for post and coronal restorations were employed.

In several previous studies, ${ }^{8-14}$ all-ceramic crowns using IPS Empress (Ivoclar Vivadent) were utilized at each tooth position, and fracture strengths were measured. Fracture strengths of maxillary first premolars and mandibular central incisors were significantly lower than for the other teeth. Lee et al. ${ }^{9}$ studied the fracture strength of all-ceramic crowns using zirconia at each tooth position. Fracture strengths of maxillary first incisors, maxillary first premolars, mandibular central incisors and mandibular canines were significantly lower than for the other teeth.

The purpose of this study was to investigate the fracture loads of natural teeth by employing simulated occlusal loading and observe the paths of fracture for the different kinds of teeth in groups such as maxillary and mandibular incisors, canine, premolars, and molars.

\section{MATERIALS AND METHODS}

One hundred and forty natural teeth were collected, which were caries-free and had not received any restorative treatment, were selected for specimens. There were a total of 14 groups with 10 teeth in each group, 5 from males and 5 from females. Each extracted tooth was numbered, and its position and the sex and age of the patient were recorded.

These tooth specimens were stored in a container, soaked in 5\% sodium hypochlorite solution for 24 hours to remove organic residues, stored in normal saline solution, and refrigerated. The saline solution was replaced every 3 days and was maintained at $37^{\circ} \mathrm{C}$ to preserve an in vivo-like environment. The design of the study was approved by the Ethical Research Committee of the Wonkwang University, Iksan, Republic of Korea.

These collected and properly stored specimens were utilized in cylindrical open molds, having $25 \mathrm{~mm} \times 25 \mathrm{~mm}$ dimensions were machined from Teflon. Acrylic resin (Ortho Jet Acrylic Resin, Lang, Wheeling, IL, USA) was poured into each mold, and the tooth was embedded with the longitudinal axis leveled and $1 \mathrm{~mm}$ lower than the cervix. A total of 140 experimental specimen molds were made for the 140 teeth.

The measurement of fracture load was carried out with a loading protocol which was designed to mimic in vivo functional loading experienced by the different types of teeth. Metal jigs were positioned at 30 degrees from the perpendicular on the embedded tooth specimens. A metal bar, which had a flat end, was attached at the center of the surface, and the load was applied to this bar. Premolar and molar teeth were inserted into the metal jigs, which were positioned at 30 degrees from the perpendicular, followed by attaching a $5 \mathrm{~mm}$ semicircular metal bar to the center of the lingual surface of the functional cusp for the maxillary tooth specimens and to the center of the buccal surface of the functional cusp for the mandibular tooth specimens. Specimens were loaded in compression, using a crosshead speed of $1 \mathrm{~mm} / \mathrm{min}$ with a universal testing machine (Model Z020, Zwick, Kennesaw, GA, USA). The load at which fracture occurred for each specimen was obtained from the load drop on the load-displacement data obtained with the computer linked to the testing machine. The fracture load value was obtained in Newton (N). From the data values, elastic modulus values were calculated. Fig. 1 provides close-up views of the loading fixtures for representative tooth specimens.

Statistical analysis was carried out by statistical comparisons of fracture loads for each type of tooth in the mandible and maxilla were performed using one-way ANOVA
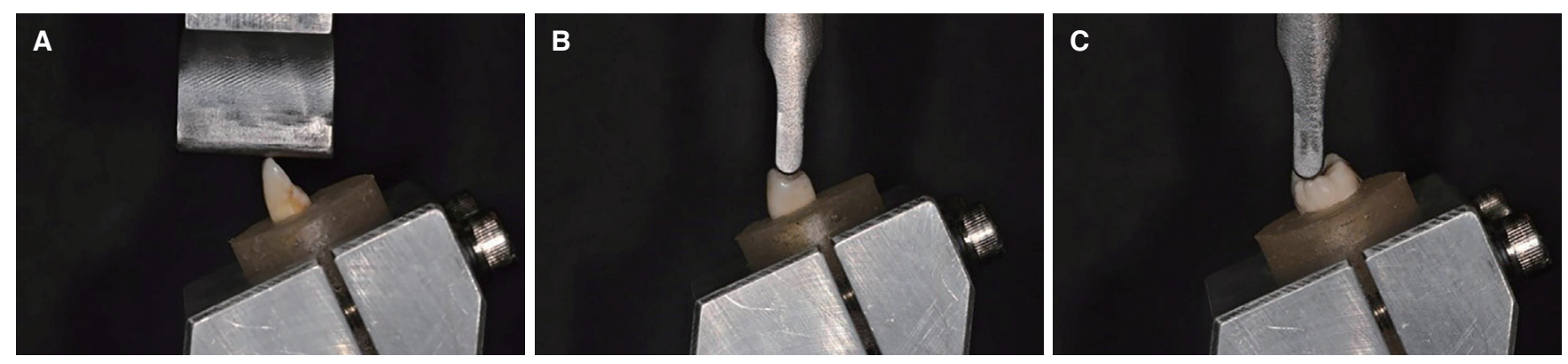

Fig. 1. (A) Fixtures employed for compression loading on incisor teeth, (B) Fixtures employed for compression loading on premolar teeth, (C) Fixtures employed for compression loading on molar teeth. 
Table 1. Results of one-way ANOVA for fracture loads of maxillary and mandibular teeth

\begin{tabular}{lrrrrr}
\hline & Sum of squares & df & Mean square & $F$ & $P$ \\
\hline Between groups & 23939444 & 13 & 1841495.7 & $19.669<.001$ \\
Within groups & 11796601 & 126 & 93623.8 & & \\
Total & 35736045 & 139 & & \\
\hline
\end{tabular}

Table 2. Results of paired t-tests for comparison fracture loads

\begin{tabular}{ccccccc}
\hline Sex & No & Mean $(\mathrm{N})$ & $\mathrm{SD}$ & $\mathrm{t}$ & $\mathrm{df}$ & \\
\hline Male & 70 & 1118.07 & 552.72 & 3.008 & 138 & .003 \\
Female & 70 & 867.39 & 424.9 & & & \\
\hline
\end{tabular}

(Version 12.0; SPSS, IBM, Chicago, IL, USA), (Table 1); Duncan multiple range test was used for post hoc comparisons $(\alpha=.05)$. Paired t-tests $(P<.05)$ were employed to compare differences in the fracture load for teeth from male and female subjects (Table 2). Correlation analyses employed Pearson coefficients for comparisons between age and fracture load for all teeth.

\section{RESULTS}

The results of fracture load on teeth were dependent on the tooth specimen position. In Fig. 2, Central Incisors, CI; Lateral Incisors, LI; Canine, C; First Premolar, P1; Second Premolar, P2; First Molar, M1; Second Molar, M2 were compared in fracture load between the maxillary and man- dibular teeth. Mandibular first premolars had the highest mean fracture load $(2002 \mathrm{~N})$, which was significantly greater than the mean fracture loads for all of the other tooth types. Maxillary premolars had the lowest mean fracture load $(525 \mathrm{~N})$. Mean fracture loads for the maxillary first and second premolars and for the maxillary and mandibular incisors were significantly lower than those for the maxillary premolars. Comparing the mean fracture loads between mandibular and maxillary teeth, there were no significant differences among the incisors, canines, and molars, while the mean fracture loads for the mandibular first premolars and second premolars were significantly higher. Duncan multiple range test confirmed the significant differences of the fracture loads between the mandibular and maxillary teeth. These results are presented in Fig. 2, and in Table 3

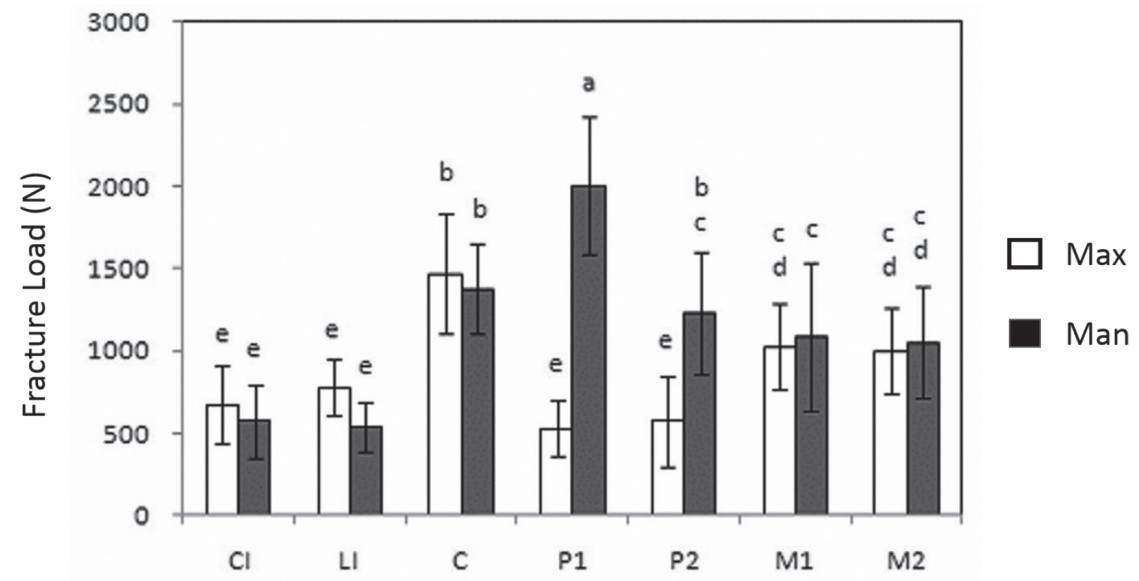

Fig. 2. Fracture loads (means and standard deviations) for maxillary (Max) and mandibular (Man) teeth. The same letter codes indicate no significant difference, using one-way ANOVA and Duncan's multiple range test. 
Table 3. Fracture loads for maxillary teeth, showing displacements in compression

\begin{tabular}{|c|c|c|c|c|c|c|}
\hline \multirow[b]{2}{*}{ Group } & \multicolumn{2}{|c|}{ Fracture load $(\mathrm{N})$} & \multicolumn{2}{|c|}{ Elastic modulus (GPa) } & \multicolumn{2}{|c|}{ Displacement $(\mu \mathrm{m})$} \\
\hline & Mean & SD & Mean & SD & Mean & SD \\
\hline Central incisor & 670 & 228 & 2.54 & 0.81 & 536 & 191 \\
\hline Lateral incisor & 773 & 149 & 3.81 & 2.08 & 546 & 200 \\
\hline Canine & 1470 & 386 & 3.42 & 0.93 & 980 & 468 \\
\hline First premolar & 525 & 167 & 0.68 & 0.26 & 403 & 89 \\
\hline Second premolar & 576 & 215 & 0.90 & 0.28 & 531 & 212 \\
\hline First molar & 1026 & 233 & 2.20 & 1.26 & 997 & 347 \\
\hline Second molar & 998 & 329 & 3.06 & 1.61 & 794 & 246 \\
\hline
\end{tabular}

Table 4. Fracture loads for mandibular teeth, showing displacements in compression

\begin{tabular}{|c|c|c|c|c|c|c|}
\hline \multirow[b]{2}{*}{ Group } & \multicolumn{2}{|c|}{ Fracture load (N) } & \multicolumn{2}{|c|}{ Elastic modulus (GPa) } & \multicolumn{2}{|c|}{ Displacement ( $\mu \mathrm{m})$} \\
\hline & Mean & SD & Mean & SD & Mean & SD \\
\hline Central incisor & 573 & 253 & 1.95 & 0.60 & 542 & 244 \\
\hline Lateral incisor & 536 & 128 & 2.03 & 1.69 & 441 & 95 \\
\hline Canine & 1377 & 216 & 3.89 & 1.65 & 1063 & 287 \\
\hline First premolar & 2002 & 429 & 2.65 & 0.86 & 1391 & 428 \\
\hline Second premolar & 1228 & 292 & 1.84 & 1.12 & 1082 & 301 \\
\hline First molar & 1089 & 440 & 2.09 & 1.26 & 978 & 446 \\
\hline Second molar & 1052 & 511 & 1.97 & 1.82 & 790 & 305 \\
\hline
\end{tabular}

Table 5. Summary of correlation analysis between age and fracture load

\begin{tabular}{lc}
\hline Pearson correlation coefficient & -306 \\
Significance of probable correlation & 0.001 \\
$\mathrm{~N}$ & 115 \\
\hline
\end{tabular}

and Table 4. The two tables also provide values of elastic modulus and the displacement in compression at which specimen fracture occurred.

Gender difference between male and female was significant. There was a significant difference between the teeth from male and female patients, with the fracture loads for the teeth from males being significantly greater $(P<.01)$.

The age difference was compared. The average age of the patients who provided the sample teeth was 43 years old (ranging from 17 to 86 years old). There was an inverse trend (Table 5) between age and fracture strength, in which older teeth had lower fracture loads compared to younger teeth $(P<.01)$.

The appearance of tooth fractures were different when the maxillary and mandibular teeth were compared. Fracture lines in the maxillary and mandibular incisors and canines began at the center of the loading point on the lingual sur- face and continued through the tooth, perpendicularly to the long axis, resulting in complete fracture at the labial surface. The molars and premolars had fracture lines that began at the center of the loading site on an inclined area of the functional cusp and extended through the tooth, perpendicularly to the long axis, resulting in fracture at the lingual surface of the maxillary teeth and at the buccal surface of the mandibular teeth.

\section{DISCUSSION}

It is expected that differences occurred according to the length, sizes of the labiolingual cervix and mesiodistal cervix, location of the pulp chamber, sizes of the roots, and levels of calcification among the extracted natural teeth used for this investigation. ${ }^{15}$ The natural tooth is a complex anisotropic, composite material, and is always in contact with saliva in vivo. Therefore, it was not possible to maintain the extracted specimen teeth in the same condition that natural teeth would possess in the oral envirfonment. ${ }^{16}$

It is important to have an artificial periodontal ligament in place when in vitro loading is imposed on a tooth specimen. ${ }^{15}$ In general, Impregum F polyether impression material (3M ESPE), denture soft reliner, or Nitoflon adhesive tape (Nitto) have been used to simulate a periodontal ligament in such mechanical testing. The latter is more commonly employed because it provides better specimen stabili- 
ty and is heat-resistant. The Nitoflon adhesive tape, typically $0.1 \mathrm{~mm}$ thick, should be wound twice around the root in order to create a $0.2-\mathrm{mm}$ thick artificial periodontal ligament. ${ }^{3}$ It should be noted that the natural teeth in the oral cavity have some perpendicular and horizontal instability due to the periodontal ligament creating some space. However, the space created by the artificial periodontal ligament was not considered in this study because the main objectives were comparisons of the fracture load with respect to age and gender.

When considering the present fracture loads for maxillary and mandibular teeth, the significantly higher mean values for the first premolar teeth of the mandible, compared to all of the other tooth types except canines, arise from differences in external shape and internal structure. Moreover, past comparisons of the fracture strength of teeth utilized prostheses subjected to occlusal loading, rather than direct measurement of the fracture loads for natural teeth. ${ }^{13}$

Present observations that (a) mean fracture loads for teeth from male patients were greater than those for teeth from female patients and (b) there was an inverse relationship between age and fracture strength such that older teeth had lower mean fracture loads are attributed to differences in shape of the teeth for male and female patients and to the teeth becoming more brittle with age, respectively. It should be noted that the number of specimens (5) in each tooth type group was equal for male and female patients and that the age distribution was similar among the different specimen groups. According to Oh's ${ }^{17}$ study, there are differences depending on race and sex of patients. The results also depend on the number of teeth, the arrangements of the teeth at specific areas, and the shapes of the roots. For example, the actual function of mastication involving molar teeth takes place at the buccolingual cusp and the external surface of the functional cusp. ${ }^{17}$

On the other hand, natural teeth in the oral cavity can experience stress fracture caused by a load less than that of the normal mean fracture load because of repetitive loading and fluctuating in vivo temperatures. Occlusal loading not only takes place perpendicularly, but also horizontally. Therefore it is difficult to predict that teeth specimen in the present in vitro study were in a more stable condition than when these teeth were originally in the oral cavity. ${ }^{18}$ For future investigations on the fracture of teeth, additional improvements in replicating in vivo conditions are essential, such as use of fluctuating loads, more aggressive media, and materials that more closely mimic the properties of the periodontal ligament and supporting alveolar bone. ${ }^{13}$ Moreover, in order to obtain values of fracture strength, rather than fracture load, finite element analyses are needed to model local conditions at the loading sites on tooth specimens. Another promising area of future in vitro research is use of a nanoindenter to obtain local values of hardness and elastic modulus for different teeth.

Due to the nature of this study, which does not accurately reflect clinical fracture conditions, further study is warranted. Despite these limitations in replicating similar aspects of the oral environment, the results showed that patient age and sex affect the fracture load for extracted teeth and that this load varies considerably for the different types of teeth. Future studies will examine the effects of direction and location of the loading on extracted teeth, which are also important variables. ${ }^{19}$

The values for elastic modulus in Table 3 and Table 4 correspond to the overall resin-mounted specimen and loading conditions, rather than only tooth structure which has much higher value..$^{20,21}$

\section{CONCLUSION}

Fracture loads observed for natural extracted teeth specimens varied depending on tooth position and were significantly higher for the first molar of the mandible. Mean fracture loads for teeth from male patients were greater than those for females. There was an inverse relationship between age and fracture load, in which older teeth had lower values compared to younger teeth. Differences in the mean fracture loads resulted from differences in the shapes and structures of the teeth.

\section{ORCID}

Jin-Keun Dong bttps://orcid.org/0000-0002-2856-1139

William Arthur Brantley https://orcid.org/0000-0002-0932-5683

David Seungho Han https://orcid.org/0000-0003-1948-1871

\section{REFERENCES}

1. Jordan RE, Abrams L, Kraus BS. Dental anatomy and occlusion. Mosby-Year Book, 1992. p. 43-66.

2. Habelitz S, Marshall SJ, Marshall GW Jr, Balooch M. Mechanical properties of human dental enamel on the nanometre scale. Arch Oral Biol 2001;46:173-83.

3. Pegoretti A, Fambri L, Zappini G, Bianchetti M. Finite element analysis of a glass fibre reinforced composite endodontic post. Biomaterials 2002;23:2667-82.

4. Strub JR, Beschnidt SM. Fracture strength of 5 different allceramic crown systems. Int J Prosthodont 1998;11:602-9.

5. Potiket N, Chiche G, Finger IM. In vitro fracture strength of teeth restored with different all-ceramic crown systems. J Prosthet Dent 2004;92:491-5.

6. Attia A, Kern M. Fracture strength of all-ceramic crowns luted using two bonding methods. J Prosthet Dent 2004;91:24752.

7. Al-Omiri MK, Mahmoud AA, Rayyan MR, Abu-Hammad O. Fracture resistance of teeth restored with post-retained restorations: an overview. J Endod 2010;36:1439-49.

8. Dong JK, Oh SC, Kim SD. Fracture strength of the IPS empress crown: The effect of occlusal depth and axial inclination on upper first premolar crowns. J Korean Acad Prosthodont 1999;37:127-33.

9. Lee IS, Kim JM, Dong JK. Fracture strength of zirconia ceramic crowns according to tooth position. J Korean Acad Prosthodont 2010;48:94-100. 
10. Lee JH, Dong JK. Enamel thickness of maxillary first premolar. J Korean Acad Stoma Func Occl 2002;18:31-8.

11. Shin DK, Kang HJ, Park YS, Park KS, Dong JK. Fracture strength of the IPS empress crown: the effects of incisal reduction and axial inclination on upper canine. J Korean Acad Prosthodont 2005;43:30-40.

12. Song BK, Lee HH, Dong JK. Fracture strength of the IPS empress crown. The effect of occlusal depth and axial inclination on upper central incisor. J Korean Acad Stoma Func Occl 2000;16:237-45.

13. Nam YS, Dong JK. Fracture strength of the IPS empress crown. The effect of incisal reduction and axial inclination on lower central incisor. J Korean Acad Stomato Func Occlu 2003;19:207-17.

14. Kim HJ, Lee HH, Nam YS, Dong JK. Fracture strength of the IPS empress crown: The effect of occlusal depth and axial inclination on lower second premolar. J Korean Acad Prosthodont 2002;40:441-50.

15. Ottl P, Hahn L, Lauer HCh, Fay M. Fracture characteristics of carbon fibre, ceramic and non-palladium endodontic post systems at monotonously increasing loads. J Oral Rehabil 2002;29:175-83.

16. Wall JG, Reisbick MH, Johnston WM. Incisal-edge strength of porcelain laminate veneers restoring mandibular incisors. Int J Prosthodont 1992;5:441-6.

17. Oh SC. A study on morphology and size of clinical crown of permanent mandibular molar in Korean adult. J Korean Acad Prosthodont 1999;37:242-55.

18. Browning JD, Meadors LW, Eick JD. Movement of three removable partial denture clasp assemblies under occlusal loading. J Prosthet Dent 1986;55:69-74.

19. Jo JH, Vang MS. Stress analysis of various esthetic restorations by finite element method. J Korean Acad Prosthodont 1991;29:129-46.

20. Stanford JW, Weigel KV, Paffenbarger GC, Sweeney WT. Compressive properties of hard tooth tissues and some restorative materials. J Am Dent Assoc 1960;60:746-56.

21. Meredith N, Sherriff M, Setchell DJ, Swanson SA. Measurement of the microhardness and Young's modulus of human enamel and dentine using an indentation technique. Arch Oral Biol 1996;41:539-45. 